\title{
Eosinophilic Gastrointestinal Diseases: The Pathogenesis, Diagnosis, and Treatment
}

\author{
Yoshikazu Kinoshita ${ }^{1,2}$, Shinsuke Yahata $^{2}$ and Sachiko Oouchi ${ }^{2}$
}

\begin{abstract}
:
Eosinophilic gastrointestinal diseases are delayed-type chronic allergic disorders that show gastrointestinal eosinophil dense infiltration, with an exaggerated Th2-type immune reaction considered to be an important mechanism. These diseases can be roughly divided into two types: eosinophilic esophagitis, mainly found in young and middle-aged men, and eosinophilic gastroenteritis, which is found in both genders equally. A diagnosis of eosinophilic esophagitis is suspected when characteristic endoscopic findings, including longitudinal furrows and rings, are noted. However, characteristic endoscopic abnormalities are rarely found in cases with eosinophilic gastroenteritis, so multiple biopsy sampling from the apparently normal gastrointestinal mucosal surface is important for making an accurate diagnosis. The administration of systemic glucocorticoid is the standard treatment for eosinophilic gastroenteritis, while acid inhibitors and topical glucocorticoid swallowing therapy are effective for eosinophilic esophagitis. Anti-cytokine therapies for eosinophilic gastrointestinal diseases are currently under development.
\end{abstract}

Key words: proton pump inhibitor, endoscopy, allergy, elimination diet

(Intern Med Advance Publication)

(DOI: 10.2169/internalmedicine.8417-21)

\section{Introduction}

Allergic diseases caused by an exaggerated or inappropriate immune response to exogenous antigens are increasing in many countries including Japan. The prevalence of three major types of allergic diseases including bronchial asthma, allergic rhinitis, and atopic dermatitis has been steadily rising, and they are now commonly encountered. Food allergies are also increasing in prevalence and regarded as one of the most important classifications of allergic disease, as anaphylactic shock can result in some cases. In addition to acute food allergy caused by an immunoglobulin E (IgE)mediated mechanism, delayed-type food allergy has been proposed as a new disease entity (1).

Eosinophilic gastrointestinal diseases are considered to be a pathologic condition caused by delayed-type food allergy and characterized by the dense infiltration of eosinophils in the esophago-gastro-intestinal tract. Recently, they have been established as a disease entity, although information con- cerning their diagnosis and treatment has not yet been widely distributed. In addition, as with other allergic diseases, the prevalence of eosinophilic gastrointestinal diseases is rapidly increasing in Japan as well as in Western countries $(2,3)$.

We herein review the pathogenesis, classification, epidemiology, diagnosis, and treatment of eosinophilic gastrointestinal diseases.

\section{Pathogenesis}

Although the pathogenesis and pathophysiology of eosinophilic gastrointestinal diseases are not completely understood, an exaggerated Th2-type immune response to exogenous antigens, especially food and airborne antigens, is considered the main etiological mechanism (4). After starting the oral administration of allergens for allergic rhinitis, up to $5 \%$ of treated patients reportedly develop an eosinophilic gastrointestinal disease $(5,6)$. However, up to $70 \%$ of affected patients can be treated by an elimination diet for

${ }^{1}$ Department of Medicine, Hyogo-Brain and Heart Center at Himeji, Japan and ${ }^{2}$ Department of Medicine, Steel Memorial Hirohata Hospital, Japan

Received: July 29, 2021; Accepted: August 29, 2021; Advance Publication by J-STAGE: October 19, 2021

Correspondence to Dr. Yoshikazu Kinoshita, kinositamove2@yahoo.co.jp 


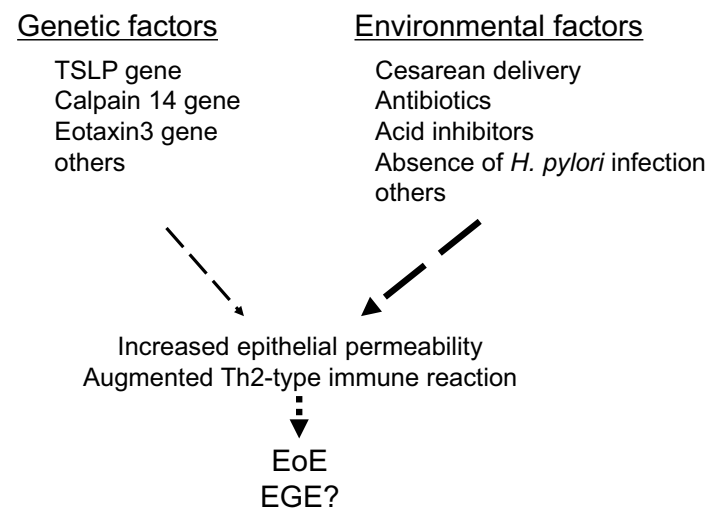

Figure 1. Influence of genetic and environmental factors on the development of eosinophilic gastrointestinal diseases.

the exclusion of several different types of allergens $(7,8)$.

Epidemiological investigations including twin and family studies have suggested that a greater contribution of environmental factors than genetic factors to the development of eosinophilic esophagitis, the most prevalent type of eosinophilic gastrointestinal disease (9-11), which provides a reasonable explanation for the recently observed rapid increase in cases with these diseases. Regarding environmental factors, proton pump inhibitors and antibiotics administered during the neonatal period and for Caesarian delivery are reported to be risk factors for the development of pediatric eosinophilic esophagitis (12-14). Those agents change the gut microbiome and suppress the adequate digestion of food antigens; furthermore, they may induce allergic reactions to ingested foods or airborne antigens $(15,16)$.

Various research attempts, including a genome-wide association study, have identified several risk-related genes. Among the reported genes, thymic stromal lymphopoietin and calpain 14 are potentially important, as their variations may influence the occurrence of eosinophilic gastrointestinal diseases by altering the Th2-type immune response and epithelial permeability to allergens (17-19).

A microarray analysis of gut mucosal biopsy specimens showed an increased expression of Th2-type cytokines, including IL-5, IL-13, and eotain3, and decreased expression of epithelial adhesion molecules, such as desmoglein (20). Furthermore, the expression of TGF- $\beta$ and periostin, cytokines related to increased remodeling and fibrosis of the gut wall, has also been reported to be increased (21).

Based on these findings, eosinophilic esophageal diseases are speculated to occur in cases with increased levels of Th2 immune reaction diathesis. When immunogenic food or airborne allergens penetrate the epithelial barrier without appropriate digestion and degradation in the gut, they can initiate Th2-type immune reactions in gastrointestinal tissues (Fig. 1).

\section{Classification}

Eosinophilic esophageal diseases are classified based on the involved segment and wall layer of the gastrointestinal tract. When dense eosinophilic infiltration is limited to the esophageal epithelial layer, the disease is classified as eosinophilic esophagitis, which is the most common eosinophilic gastrointestinal disease in Japan as well as Western countries (3). When pathologically dense infiltration and activation of eosinophils is identified in other segments of the gastrointestinal tract, the disease is classified as eosinophilic gastroenteritis, irrespective of esophageal eosinophil infiltration. Eosinophilic gastroenteritis may then be further classified as eosinophilic gastritis, eosinophilic duodenitis, eosinophilic ileitis, or eosinophilic colitis depending on the segment involved (Fig. 2).

Eosinophil infiltration can occur in any layer of the gastrointestinal tract, including mucosal, muscle, and subserosal layers, so eosinophilic gastrointestinal diseases are classified based on the involved layer, such as mucosal, muscle layer, and sub-serosal types (22). However, the mechanisms by which pathological eosinophil infiltration occurs in various segments and layers of the gastrointestinal tract have not been elucidated.

\section{Epidemiology}

Epidemiological data for eosinophilic esophagitis and eosinophilic gastroenteritis differ in several aspects (Table 1). In Western countries, the incidence and prevalence of eosinophilic esophagitis are reported to be approximately 10 and 50, respectively, per 100,000 individuals in the general population (23). Its prevalence in Japan is considered to be increasing rapidly $(2,24,25)$, and several reports that analyzed cases examined with endoscopy have suggested the rate of prevalence to be as high as noted in Western studies $(24,25)$. However, to our knowledge, the prevalence of eosinophilic esophagitis in the general Japanese population has not yet been investigated. Regarding eosinophilic gastroenteritis, its prevalence in Western countries is lower than that of eosinophilic esophagitis and reported to range from 2 to 8 per 100,000 in the general population $(26,27)$. In Japan as well, the prevalence of eosinophilic esophagitis has recently become higher than that of eosinophilic gastroenteritis due to an increasing trend in the diagnosis $(3,28)$.

Regarding affected ages and gender, eosinophilic esophagitis is found most frequently in middle-age (30-50 years) men with a man-to-woman ratio of 4-5 to 1 . In contrast, eosinophilic gastroenteritis is found similarly in all age groups, and the gender ratio is reported to be roughly equal $(26,28)$. These different epidemiological characteristics suggest a similar but unique pathogenesis for these two types of eosinophilic gastrointestinal disease.

\section{The Diagnosis}

The diagnosis of eosinophilic gastrointestinal diseases is based on a precise collection of the medical history, appropriate physical examinations, laboratory tests of peripheral 
$\underline{\text { Neonates and infants }}$

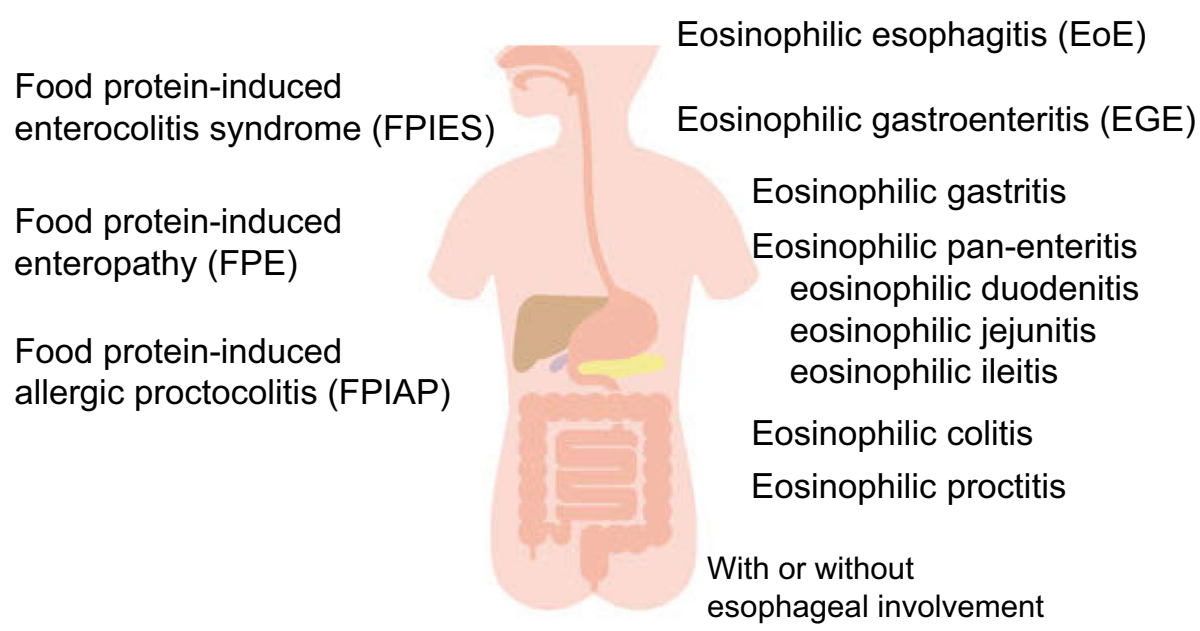

\section{Adults}

esophageal involvement

Figure 2. Classification of eosinophilic gastrointestinal diseases.

Table 1. Diagnosis of Eosinophilic Esophagitis (EoE) and Eosinophilic Gastroenteritis (EGE).

\begin{tabular}{lcc}
\hline & EoE & EGE \\
\hline Age & $30-50$ years & All ages \\
Male/female ratio & $4: 1$ & $1: 1$ \\
Symptoms & Dysphagia & Abdominal pain \\
& Heartburn & Nausea/vomiting \\
Laboratory tests & Eosinophilia 30\% & Diarrhea \\
& & Eosinophilia $80 \%$ \\
Endoscopy & Characteristics & Elevated TARC \\
& longitudinal furrows & Non-specific \\
& white plaque & normal>60\% \\
& rings & edema \\
CT & others & redness \\
& Rare & erosion/ulcer \\
Histology & Frequent \\
& Eosinophils $>15 /$ HPF & No consensus regarding \\
& Basal zone hyperplasia & eosinophil density \\
& Dilated intracellular space & Intraepithelial eosinophils \\
Papilla elongation & Villous atrophy \\
& Surface layering of eosinophils & Crypt hyperplasia \\
Eosinophilic microabscess & Eosinophilic abscess \\
& Mast cell infiltration & Mast cell infiltration \\
& others & others \\
\hline & & segmental thickening of gut \\
& & ascites \\
& &
\end{tabular}

blood, a gastrointestinal endoscopic study, and the results of a histopathological examination of biopsy specimens (Table 1). Notably, taking the medical history for subjective symptoms and the histopathological detection of dense eosinophil infiltration in the gut wall are considered to be especially important (29).

\section{Medical history collection}

Half of patients with eosinophilic gastrointestinal diseases are affected by at least one atopic disease, such as bronchial asthma, allergic rhinitis, atopic dermatitis, and IgE-mediated food allergy. Therefore, taking the history with a focus on atopic diseases is important $(2,3,28)$.

Adults with eosinophilic esophagitis mainly complain of dysphagia and heartburn, while pediatric cases are often affected by non-specific symptoms, such as abdominal pain. Patients with eosinophilic gastroenteritis will note epigastralgia, nausea, and/or vomiting if they have gastro-duodenal lesions, whereas those with eosinophilic gastroenteritis have ileal and/or colonic lesions and will be affected by diarrhea 
and lower abdominal pain. Noting the presence of these bothersome symptoms is considered necessary for an accurate diagnosis of eosinophilic gastrointestinal diseases (29).

\section{A physical examination}

Although the role of physical examination findings in the diagnosis of eosinophilic gastrointestinal diseases is not substantial, skin lesions suggesting atopic dermatitis and signs suggesting intestinal inflammation may be detected.

\section{Laboratory tests}

Peripheral blood eosinophilia can be found in approximately one-third of cases of eosinophilic esophagitis, although the grade of eosinophilia is very mild and easily overlooked (Table 1). In contrast to eosinophilic esophagitis, $80 \%$ of patients with eosinophilic gastroenteritis show peripheral eosinophilia, and its severity grade is higher than eosinophilic esophagitis (28). In addition to peripheral eosinophilia, the plasma IgE concentration is elevated in $70 \%$ of patients with eosinophilic gastrointestinal diseases. Furthermore, higher concentrations of an antigen-specific IgE against various foods and airborne antigens, including pollen, are frequently observed in patients with these diseases $(28,30)$. Thus, eosinophilia, as well as specific and non-specific findings indicating an increased IgE concentration in plasma are suggestive of atopic diathesis in eosinophilic gastrointestinal disease cases.

The prevalence of Helicobacter pylori infection has been shown to be lower in patients with eosinophilic esophagitis as well as those with eosinophilic gastroenteritis than in control populations $(31,32)$. An elevated Th1 immune reaction, observed in cases with $H$. pylori infection, may inhibit the Th2 immune response, which is necessary for the development of eosinophilic gastrointestinal diseases.

To determine possible peripheral blood biomarkers for the diagnosis as well as grading of disease activity, the concentrations of various cytokines were measured and compared with those in healthy individuals $(33,34)$. Although eotaxin 3, IL-5, IL-13, and thymic stromal lymphopoietin (TSLP) showed elevated peripheral blood concentrations in patients with eosinophilic gastrointestinal diseases, marked overlap was seen with values in the healthy subjects in those studies, indicating their limited utility as biomarkers. Nevertheless, TSLP and IL33 are being further investigated as potential biomarkers of infantile eosinophilic gastroenteritis (35). At present, a diagnosis based on blood biomarkers is considered to be difficult.

When ascitic fluid is present, a large number of eosinophils in ascites may be found, a sign of sub-serosal type of eosinophilic gastroenteritis. Eosinophil-associated protein concentrations measured in esophageal mucosal surface fluid collected by a swallowed string can be used to diagnose eosinophilic esophagitis (36). In addition, the examination of stool samples to determine the concentrations of eosinophil granular proteins, including eosinophil-derived neurotoxin, can also be utilized, as those are diagnostic markers of esophageal gastrointestinal diseases (37). The nitric oxide concentration in exhaled breath has also been reported to be a potential biomarker for eosinophilic esophagitis, although research data concerning this point remain inadequate $(38,39)$.

Although each of these laboratory tests can be useful for the diagnosis and grading of eosinophilic gastrointestinal disease activity, their value remains limited, and further studies are necessary.

\section{Radiology}

Plain chest and abdominal X-ray are not sensitive enough to detect abnormalities in cases with eosinophilic gastrointestinal diseases. In contrast, computed tomography (CT) is useful, and its diagnostic yield is high, especially for determining eosinophilic gastroenteritis. In cases with eosinophilic esophagitis, esophageal wall thickening may be detected by CT. However, in eosinophilic gastroenteritis cases, segmental gut wall thickening and collection of ascites, signs indicating the sub-serosal type, are frequently observed as abnormal findings.

\section{Endoscopy}

The diagnostic value of endoscopic examination findings varies among the different types of eosinophilic gastrointestinal diseases (Table 1).

-For the diagnosis of eosinophilic esophagitis

These findings have been shown to be useful and provide important clues for the diagnosis of eosinophilic esophagitis. Longitudinal furrows, frequently found on the lower esophageal mucosal surface between longitudinal esophageal folds, are a characteristic finding noted in $90 \%$ of cases (40-42). Furthermore, white plaque and localized esophageal constriction, termed rings, are also frequently observed. These three findings of longitudinal furrows, white plaque, and rings are considered important endoscopic findings for the detection of eosinophilic esophagitis (2).

In addition to those major findings, a crepe paper-like appearance suggesting epithelial fragility (43), pull sign suggesting subepithelial fibrosis (44), and Ankylosaurus back sign suggesting a favorable response to proton pump inhibitor administration (45) have been reported. A crepe paperlike appearance is noted when a wide portion of epithelial tissue can be removed as a sheet during biopsy sample collection from the mucosal surface, while the pull sign refers to the sensation of resistance when pulling the forceps to obtain a tissue sample. Evidence of longitudinally arrayed whitish epithelial thickening resembling the nodules found on the back of a dinosaur is referred to as Ankylosaurus back sign.

To confirm the histopathological diagnosis of eosinophilic esophagitis, at least four biopsy specimens are reportedly necessary for an accurate diagnosis with minimal possibility of a false-negative result (46). Biopsy specimens obtained from the lower segment of the esophagus tend to have denser eosinophil infiltration than those obtained from the 


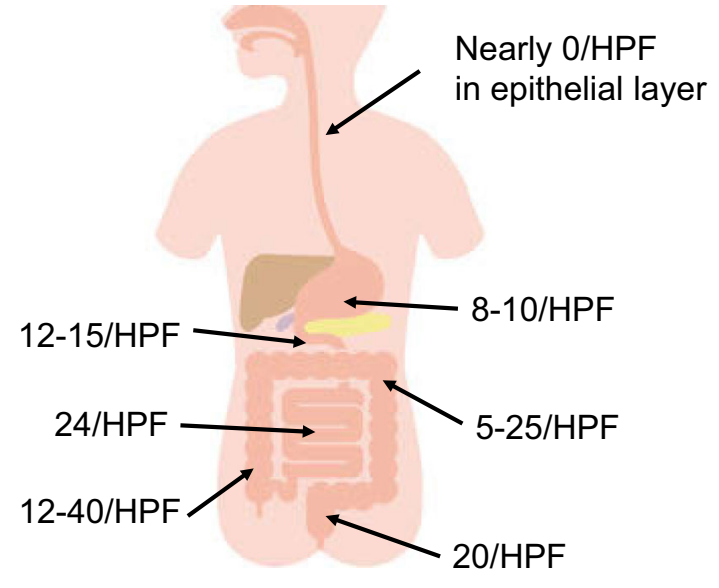

Figure 3. Maximal eosinophil infiltration in different segments of the gastrointestinal tract in a normal healthy individual.

upper segment (25). In addition, specimens obtained from lesions shown by endoscopy as longitudinal furrows or white plaque also tend to have denser eosinophil infiltration than specimens obtained from apparently normal mucosa (42). Therefore, biopsy specimens should be obtained from different sites, mainly in the lower esophagus as well as from lesions identifiable by endoscopy, to ensure the most accurate pathological diagnosis.

-For the diagnosis of eosinophilic gastroenteritis

In contrast to eosinophilic esophagitis, no endoscopic abnormalities are detected in $60 \%-70 \%$ of patients with eosinophilic gastroenteritis, regardless of the gastrointestinal tract segment $(47,48)$. Histological results often show dense eosinophil infiltration in these endoscopically normalappearing segments. Endoscopic abnormalities found in cases with eosinophilic gastroenteritis include mucosal edema, redness, erosion, ulcers, and nodularity (Table 1) (48). However, such abnormalities are generally nonspecific, and these endoscopic findings are associated with many different types of gastrointestinal disease.

The frequent absence of an endoscopic abnormality and non-specific findings make the endoscopic diagnosis of eosinophilic gastroenteritis difficult and distinct from eosinophilic esophagitis. As a result, multiple biopsy samples obtained from different gastrointestinal mucosa sites are necessary for the diagnosis of eosinophilic gastroenteritis, irrespective of the presence of specific endoscopic findings. Unfortunately, whether or not samples obtained from lesions identifiable by endoscopy show greater levels of eosinophil infiltration has not been clarified. It is important to note that samples taken from apparently normal mucosa frequently show eosinophil infiltration in pathological results.

\section{Histopathology}

To obtain appropriate histological examination results, the biopsy samples must be properly processed. Sections taken perpendicular to the surface of mucosa are necessary for counting the number of infiltrated eosinophils in different layers of the mucosa. Physical pressure applied to a sample just after obtaining it may facilitate eosinophil and/or mast cell degranulation, hampering identification. Various histopathological abnormalities in addition to increased eosinophil infiltration in cases with eosinophilic esophagitis as well as those with eosinophilic gastroenteritis have also been reported $(49,50)$.

-For the diagnosis of eosinophilic esophagitis

For the diagnosis of eosinophilic esophagitis, eosinophil infiltration $>15$ eosinophils/high-power field (HPF) (x400) in the esophageal epithelial layer in at least 1 microscopic field is necessary (51), although just one field with dense eosinophil infiltration is considered adequate for a diagnosis. In addition to dense eosinophil infiltration in the epithelial layer, mast cell infiltration, basal cell zone hyperplasia, and dilated intercellular space in the epithelial layer have also been reported in affected patients. Epithelial papilla elongation and subepithelial dense fibrosis can be observed when a denser mucosal layer is obtained from the esophagus (52). In these patients, eosinophil infiltration is mainly found in the epithelial layer, whereas no eosinophil infiltration is found in normal healthy individuals. Rarely, dense eosinophil infiltration is found only in a muscle layer with impaired esophageal motility and can be classified as eosinophilic esophageal myositis. This type of esophageal eosinophil infiltration is considered as a muscle layer type of eosinophilic esophagitis (53).

The gene expression pattern in biopsy specimens functions as a more sensitive and specific diagnostic marker of eosinophilic esophagitis than histopathological observation. An eosinophilic esophagitis diagnostic panel was shown able to determine the expression of more than 90 different messenger RNAs in esophageal mucosa and was used to suggest a diagnosis. This messenger RNA panel has also been reported to be more sensitive than the histological measurement of eosinophil infiltration and requires only a single biopsy specimen for an accurate diagnosis (54-56).

-For the diagnosis of eosinophilic gastroenteritis

Eosinophilic gastroenteritis can be associated with increased eosinophil infiltration in the lamina propria, intraepithelial eosinophils, eosinophils in Peyer's patches, degranulation of eosinophils, extracellular deposition of eosinophil granular proteins, villous atrophy, crypt hyperplasia, eosinophil abscess, and mast cell infiltration (49). The number of eosinophils present in the lamina propria of different segments of the gastrointestinal tract in normal healthy individuals has been reported by several investigators $(57,58)$. In the esophageal epithelial layer of healthy subjects, no eosinophil infiltration is shown, whereas in the stomach, duodenum, distal ileum, ascending colon, descending colon, and rectum, eosinophil infiltration up to 10, 20, 30, 30, 20, and 10 per HPF field, respectively, can be found (Fig. 3). The density of eosinophil infiltration is greatest in the distal ileum and ascending colon and then becomes lower in the more oral and anal segments of the gastrointestinal tract. Therefore, the infiltration of eosinophils should be evaluated 
Table 2. Treatment of Eosinophilic Esophagitis (EoE) and Eosinophilic Gastroenteritis (EGE).

\begin{tabular}{lcc}
\hline Erugs & PPI & EGE \\
\hline Vonoprazan & $\begin{array}{c}\text { Systemic glucocorticoid } \\
\text { Topical glucocorticoid } \\
\text { Topical glucocorticoid } \\
\text { fluticasone } \\
\text { budesonide }\end{array}$ & $\begin{array}{c}\text { Anti-allergic drugs } \\
\text { montelukast }\end{array}$ \\
& Systemic glucocorticoid & histamine H1 receptor antagonist \\
Dietary therapy & Six-food elimination diet & \\
& Four-food elimination diet & Elimination diet \\
Two-food elimination diet & Elemental diet \\
Targeted elimination diet & Elemental diet & \\
Bther therapy & Balloon dilatation & Surgery for perforation or obstruction \\
\hline
\end{tabular}

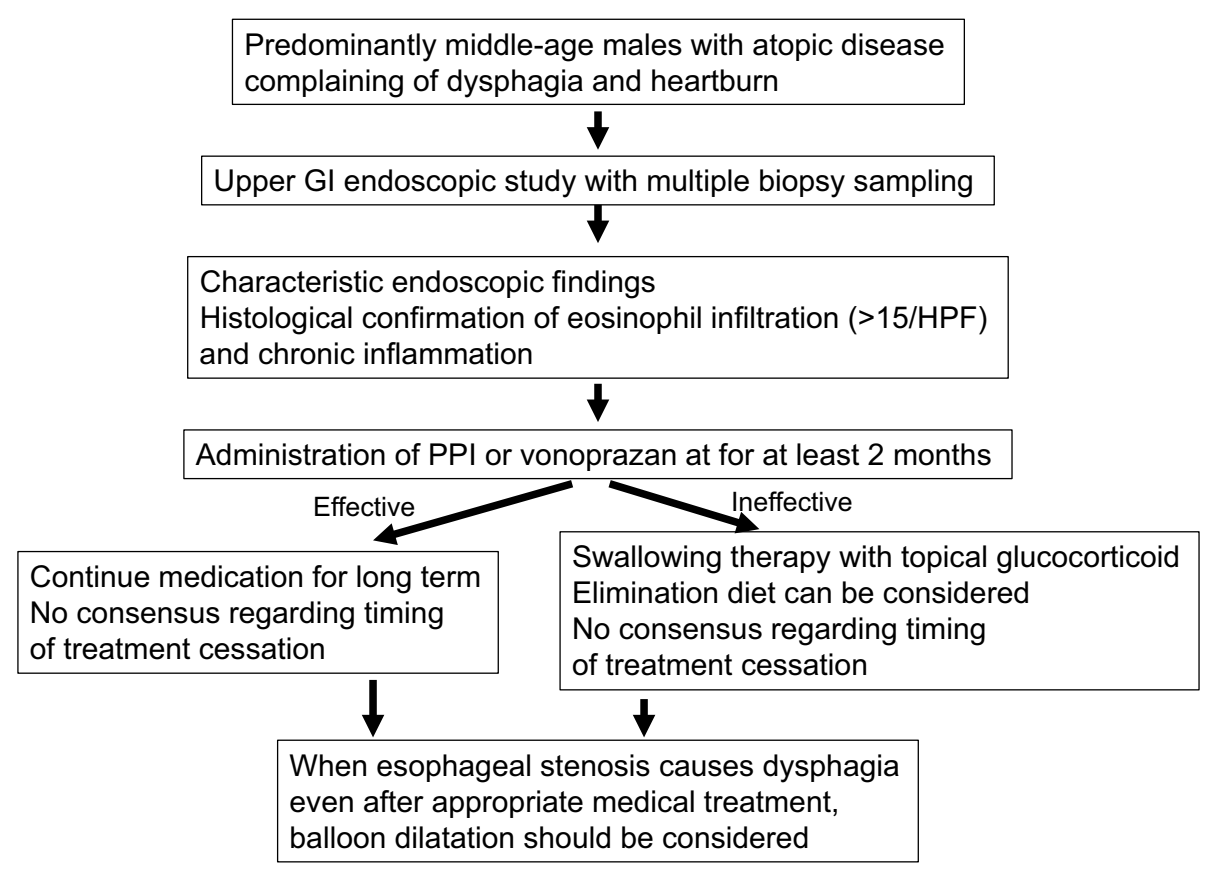

Figure 4. Flowchart of the diagnosis and treatment of eosinophilic esophagitis.

in consideration of the segment from which the biopsy specimens were taken.

A consensus has not yet been reached regarding the optimum cut-off points for the pathological density of eosinophil infiltration in each segment of the gastrointestinal tract, so other histopathological findings, including intraepithelial eosinophils, should be considered for the histological diagnosis of eosinophilic gastroenteritis different from that of eosinophilic esophagitis.

\section{Treatment}

The therapeutic responses to treatments differ between eosinophilic esophagitis and eosinophilic gastroenteritis (Table 2). For eosinophilic esophagitis, the response rate to remission induction therapy is usually good, and maintenance therapy is also successful in the majority of cases (59). In contrast, difficulties with remission and maintenance treat- ment are often encountered with eosinophilic gastroenteritis $(60)$.

\section{Treatment of eosinophilic esophagitis}

The first-line treatment for eosinophilic esophagitis is the administration of a gastric acid inhibitor, such as a highdose proton pump inhibitor, or vonoprazan, a potassium competitive acid blocker (Fig. 4). Therapy with a proton pump inhibitor for 2 months induces remission in over $50 \%$ of patients with eosinophilic esophagitis $(61,62)$, while vonoprazan treatment is also reported to be more or as effective as that with proton pump inhibitors $(63,64)$. Cases in which esophageal eosinophil infiltration can be treated by the administration of a proton pump inhibitor are termed proton pump inhibitor-responsive esophageal eosinophilia, and in the past, these cases were separated from eosinophilic esophagitis. However, several recent studies have indicated that the clinical, endoscopic, and histopathological character- 


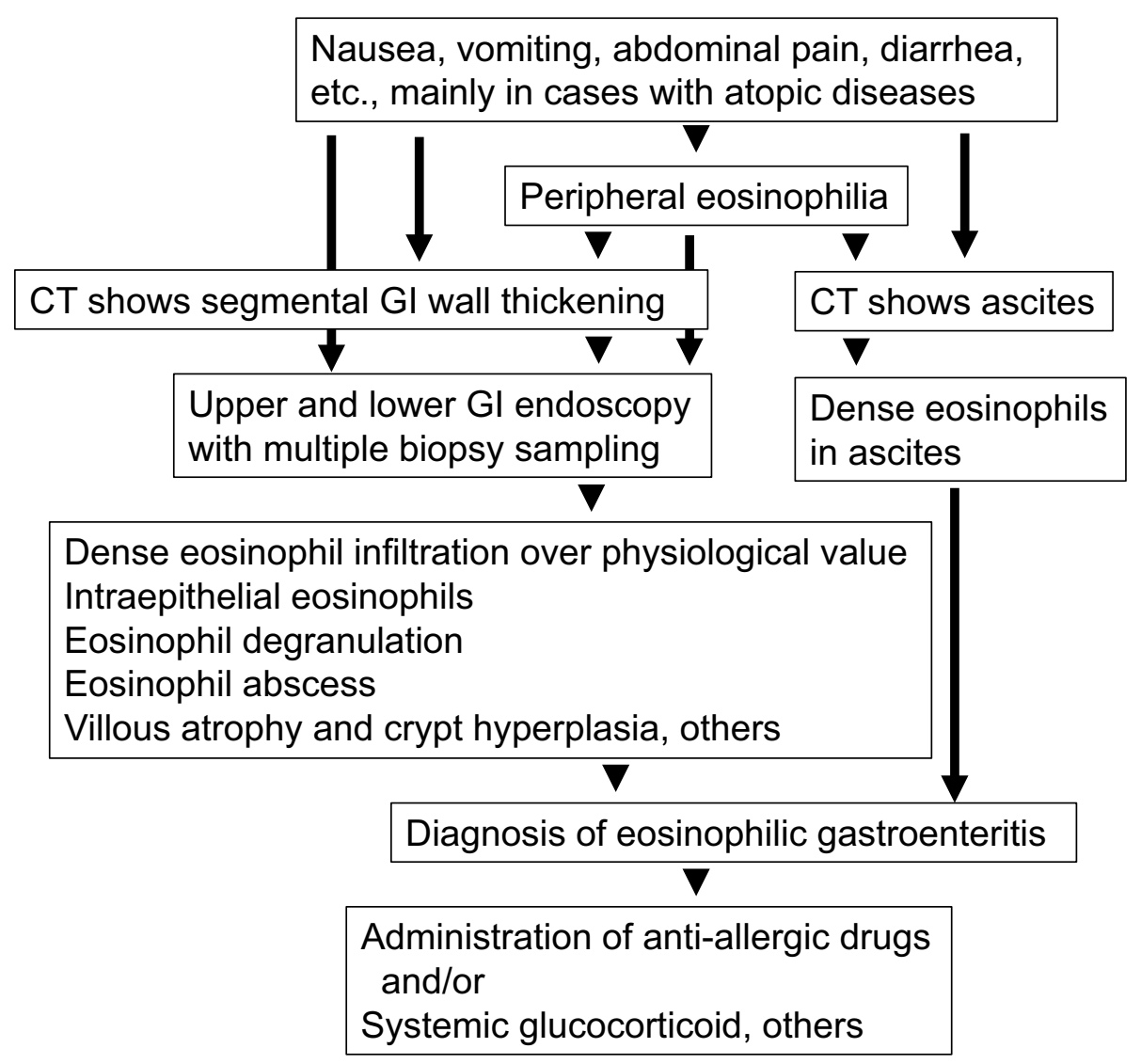

Figure 5. Flowchart of the diagnosis and treatment of eosinophilic gastroenteritis.

istics of these two diseases are quite similar, and their gene expression patterns nearly the same $(41,65)$. Therefore, esophageal eosinophil infiltration irrespective of responsiveness to acid inhibitors is diagnosed as eosinophilic esophagitis when some symptoms potentially originating from the esophageal abnormalities are noted by the patient (61). The mechanism by which acid inhibitors cause remission of eosinophilic esophagitis has not been clarified. However, an acid inhibitor-related decrease in esophageal acid exposure and resulting decrease in esophageal mucosal permeability caused by physiological or pathological esophageal acid reflux must be considered $(66,67)$.

When proton pump inhibitor or vonoprazan administration is not adequately effective, second-line treatment is necessary. Two possible options are peroral administration of a topical glucocorticoid and an elimination diet. Oral administration of a topical glucocorticoid, such as fluticasone or budesonide, and slow swallowing of a glucocorticoid twice a day results in remission in over $70 \%$ of examined cases $(68,69)$. However, continued maintenance treatment is necessary for long-term disease control, and the interruption of administration is followed by immediate exacerbation $(70,71)$. In contrast, an elimination diet may be effective for remission induction and long-term control. The effective elimination of allergic foods based on peripheral blood allergen-specific IgE concentrations or skin prick or patch tests is reportedly difficult $(62,72)$. Therefore, the empirical elimination of the six most frequently observed aller- gic foods is recommended. A six-food elimination diet excludes dairy products, soy, eggs, wheat, nuts, and seafood. Approximately $70 \%$ of patients with eosinophilic esophagitis treated with a 6-food empirical elimination diet are reported to enter a state of remission (73). Once the elimination diet has been shown to be effective, it is then possible to detect the responsible food by returning each food into the diet one by one.

\section{Treatment of eosinophilic gastroenteritis}

Anti-allergic drugs including histamine $\mathrm{H} 1$ receptor and leukotriene receptor antagonists, as well as mast cell stabilizers have been used to treat eosinophilic gastroenteritis, although evidence supporting their effectiveness is lacking (Fig. 5). Based on limited study data currently available, montelukast may be effective $(75,76)$. Systemic glucocorticoid administration has traditionally been used for remission induction therapy, with favorable results shown. According to previous reports, approximately $40 \%$ of patients with eosinophilic gastroenteritis show a complete response to glucocorticoid therapy, and no recurrence is observed after stopping administration (60). Another $40 \%$ of patients show a good response to remission induction therapy with a glucocorticoid, although their disease activity returns after stopping administration, while the remaining 20\% show resistance to such therapy, and their disease activity cannot be controlled. For these cases, various immune-modulating therapies have been reported to be effective, although addi- 
tional evidence is needed.

\section{Therapy under development}

For the treatment of refractory cases with eosinophilic esophagitis or eosinophilic gastroenteritis, new moleculartargeted therapies focusing on Th2 immune reaction are under development (77). Placebo-controlled randomized studies have presented promising results demonstrating the therapeutic efficacy of anti- $\alpha 4 \beta$ Bintegrin (78), anti-IL-5 (79), anti-IL-13 (80), anti-IL4/13 receptor (81), and anti-siglec8 (82) antibodies. Clinical research investigations concerning these new anti-cytokine therapies are currently in progress in Japan.

\section{Summary}

The eosinophilic gastrointestinal diseases of eosinophilic esophagitis and eosinophilic gastroenteritis are chronic delayed-type allergic diseases caused mainly by food and airborne antigens. Their prevalence is increasing in Japan as well as in Western countries, along with several other allergic diseases. For the diagnosis, the presence of gastrointestinal symptoms and identification of gastrointestinal eosinophil infiltration in histopathological results are necessary. The first-line treatment for eosinophilic esophagitis is the administration of a proton pump inhibitor or potassiumcompetitive acid inhibitor. When such efforts are not adequately effective, topical glucocorticoid administration or an elimination diet is usually selected as a second-line treatment option. For the treatment of eosinophilic gastroenteritis, glucocorticoid administration is the most widely used. Anti-Th2 cytokine therapies are currently under development for refractory cases of eosinophilic esophagitis or eosinophilic gastroenteritis.

The authors state that they have no Conflict of Interest (COI).

\section{Funding}

There is no funding to report with regard to this review article.

\section{References}

1. Cianferoni A, Cianferoni A. Eosinophilic esophagitis and other eosinophilic disorders of the gastrointestinal tract. Pediatr Allergy Immunol Suppl 24: 25-27, 2020.

2. Kinoshita Y, Ishimura N, Oshima N, Ishihara S. Systematic review: Eosinophilic esophagitis in Asian countries. World J Gastroenterol 21: 8433-8440, 2015.

3. Yamamoto M, Nagashima S, Yamada Y, et al. Comparison of Non-esophageal Eosinophilic Gastrointestinal Disorders with Eosinophilic Esophagitis: A Nationwide Survey. J Allergy Clin Immunol Pract 29: S2213-2198(21)00714-5, 2021. Online ahead of print.

4. Kinoshita Y, Oouchi S, Fujisawa T. Eosinophilic gastrointestinal diseases - Pathogenesis, diagnosis, and treatment. Allergol Int 68: 420-429, 2019.

5. Kawashima K, Ishihara S, Masuhara M, et al. Development of eosinophilic esophagitis following sublingual immunotherapy with cedar pollen extract: A case report. Allergol Int 67: 515-517, 2018.

6. Petroni D, Spergel JM. Eosinophilic esophagitis and symptoms possibly related to eosinophilic esophagitis in oral immunotherapy. Ann Allergy Asthma Immunol 120: 237-240.e4, 2018.

7. Wolf WA, Jerath MR, Sperry SL, Shaheen NJ, Dellon ES. Dietary elimination therapy is an effective option for adults with eosinophilic esophagitis. Clin Gastroenterol Hepatol 12: 1272-1279, 2014.

8. Okimoto E, Ishimura N, Okada M, et al. Successful FoodElimination Diet in an Adult with Eosinophilic Gastroenteritis. ACG Case Rep J 5: e38, 2018.

9. Alexander ES, Martin LJ, Collins MH, et al. Twin and family studies reveal strong environmental and weaker genetic cues explaining heritability of eosinophilic esophagitis. J Allergy Clin Immunol 134: 1084-1092.e1, 2014.

10. Allen-Brady K, Firszt R, Fang JC, Wong J, Smith KR, Peterson KA. Population-based familial aggregation of eosinophilic esophagitis suggests a genetic contribution. J Allergy Clin Immunol 140: 1138-1143, 2017.

11. Peterson K, Clayton F, Qeadan F, et al. Esophageal Eosinophilia Is Common Among Relatives of Eosinophilic Esophagitis Patients. Clin Gastroenterol Hepatol S1542-3565(20)31557-3, 2020. Online ahead of print.

12. Jensen ET, Dellon ES. Environmental factors and eosinophilic esophagitis. J Allergy Clin Immunol 142 (1): 32-40, 2018.

13. Jensen ET, Kuhl JT, Martin LJ, Langefeld CD, Dellon ES, Rothenberg ME. Early-life environmental exposures interact with genetic susceptibility variants in pediatric patients with eosinophilic esophagitis. J Allergy Clin Immunol 141: 632-637.e5, 2018.

14. Jensen ET, Kuhl JT, Martin LJ, Rothenberg ME, Dellon ES. Prenatal, intrapartum, and postnatal factors are associated with pediatric eosinophilic esophagitis. J Allergy Clin Immunol 141: 214-222, 2018.

15. Untersmayr E, Bakos N, Schöll I, et al. Anti-ulcer drugs promote IgE formation toward dietary antigens in adult patients. FASEB J 19: 656-658, 2005.

16. Pali-Schöll I, Jensen-Jarolim E. Anti-acid medication as a risk factor for food allergy. Allergy 66 (4): 469-477, 2011.

17. Rothenberg ME, Spergel JM, Sherrill JD, et al. Common variants at 5 q22 associate with pediatric eosinophilic esophagitis. Nat Genet 42: 289-291, 2010.

18. Kottyan LC, Davis BP, Sherrill JD, et al. Genome-wide association analysis of eosinophilic esophagitis provides insight into the tissue specificity of this allergic disease. Nat Genet 46: 895-900, 2014.

19. Sleiman PM, Wang ML, Cianferoni A, et al. GWAS identifies four novel eosinophilic esophagitis loci. Nat Commun 5: 5593, 2014.

20. Shoda T, Morita H, Nomura I, et al. Comparison of gene expression profiles in eosinophilic esophagitis (EoE) between Japan and Western countries. Allergol Int 64: 260-265, 2015.

21. Wen T, Stucke EM, Grotjan TM, et al. Molecular diagnosis of eosinophilic esophagitis by gene expression profiling. Gastroenterology 145: 1289-1299, 2013.

22. Talley NJ, Shorter RG, Phillips SF, Zinsmeister AR. Eosinophilic gastroenteritis: a clinicopathological study of patients with disease of the mucosa, muscle layer, and subserosal tissues. Gut 31: 5458, 1990.

23. Dellon ES, Hirano I. Epidemiology and Natural History of Eosinophilic Esophagitis. Gastroenterology 154: 319-332.e3, 2018.

24. Fujishiro H, Amano Y, Kushiyama Y, Ishihara S, Kinoshita Y. Eosinophilic esophagitis investigated by upper gastrointestinal endoscopy in Japanese patients. J Gastroenterol 46: 1142-1144, 2011.

25. Adachi K, Mishiro T, Tanaka S, Kinoshita Y. Suitable biopsy site for detection of esophageal eosinophilia in eosinophilic esophagitis suspected cases. Dig Endosc 28: 139-144, 2016. 
26. Jensen ET, Martin CF, Kappelman MD, Dellon ES. Prevalence of Eosinophilic Gastritis, Gastroenteritis, and Colitis: Estimates From a National Administrative Database. J Pediatr Gastroenterol Nutr 62: 36-42, 2016.

27. Mansoor E, Saleh MA, Cooper GS. Prevalence of Eosinophilic Gastroenteritis and Colitis in a Population-Based Study, From 2012 to 2017. Clin Gastroenterol Hepatol 15: 1733-1741, 2017.

28. Kinoshita Y, Furuta K, Ishimaura N, et al. Clinical characteristics of Japanese patients with eosinophilic esophagitis and eosinophilic gastroenteritis. J Gastroenterol 48: 333-339, 2013.

29. Lucendo AJ, Molina-Infante J, Arias Á, et al. Guidelines on eosinophilic esophagitis: evidence-based statements and recommendations for diagnosis and management in children and adults. United European Gastroenterol J 5: 335-358, 2017.

30. Ishimura N, Furuta K, Sato S, Ishihara S, Kinoshita Y. Limited role of allergy testing in patients with eosinophilic gastrointestinal disorders. J Gastroenterol Hepatol 28: 1306-1313, 2013.

31. Furuta K, Adachi K, Aimi M, et al. Case-control study of association of eosinophilic gastrointestinal disorders with Helicobacter pylori infection in Japan. J Clin Biochem Nutr 53: 60-62, 2013.

32. Zhang L, Duan L, Ding S, et al. Eosinophilic gastroenteritis: clinical manifestations and morphological characteristics, a retrospective study of 42 patients. Scand J Gastroenterol 46: 1074-1080, 2011.

33. Kinoshita Y, Furuta K, Ishimura N, Ishihara S. Elevated plasma cytokines in Japanese patients with eosinophilic esophagitis and gastroenteritis. Digestion 86: 238-243, 2012.

34. Ishihara $\mathrm{S}$, Shoda $\mathrm{T}$, Ishimura $\mathrm{N}$, et al. Serum Biomarkers for the Diagnosis of Eosinophilic Esophagitis and Eosinophilic Gastroenteritis. Intern Med 56: 2819-2825, 2017.

35. Shoda T, Matsuda A, Arai K, et al. Sera of patients with infantile eosinophilic gastroenteritis showed a specific increase in both thymic stromal lymphopoietin and IL-33 levels. J Allergy Clin Immunol 138: 299-303, 2016.

36. Ackerman SJ, Kagalwalla AF, Hirano I, et al. One-Hour Esophageal String Test: A Nonendoscopic Minimally Invasive Test That Accurately Detects Disease Activity in Eosinophilic Esophagitis. Am J Gastroenterol 114: 1614-1625, 2019.

37. Subbarao G, Rosenman MB, Ohnuki L, et al. Exploring potential noninvasive biomarkers in eosinophilic esophagitis in children. J Pediatr Gastroenterol Nutr 53: 651-658, 2011.

38. Lanz MJ, Guerrero RA, Gonzalez-Vallina R. Measurement of exhaletd nitric oxide in the evaluation for eosinophilic esophagitis in children. Ann Allergy Asthma Immunol 109: 81-82, 2012.

39. Johnson K, Iyer V, Katzka D, et al. Poor Relationship Between Fractionated Exhaled Nitric Oxide and Disease Activity in Eosinophilic Esophagitis. Dysphagia 34: 138-144, 2019.

40. Shimura S, Ishimura N, Tanimura T, et al. Reliability of symptoms and endoscopic findings for diagnosis of esophageal eosinophilia in a Japanese population. Digestion 90: 49-57, 2014.

41. Jiao D, Ishimura N, Maruyama R, et al. Similarities and differences among eosinophilic esophagitis, proton-pump inhibitorresponsive esophageal eosinophilia, and reflux esophagitis: comparisons of clinical, endoscopic, and histopathological findings in Japanese patients. J Gastroenterol 52: 203-210, 2017.

42. Okimoto E, Ishimura N, Okada M, et al. Specific locations of linear furrows in patients with esophageal eosinophilia. Dig Endosc 29: 49-56, 2017.

43. Matsuura H, Muro S, Yamauchi K. Eosinophilic Esophagitis: Crepe Paper-Like Appearance. Am J Med 131: e99-e100, 2018.

44. Dellon ES, Gebhart JH, Higgins LL, Hathorn KE, Woosley JT, Shaheen NJ. The esophageal biopsy "pull" sign: a highly specific and treatment-responsive endoscopic finding in eosinophilic esophagitis (with video). Gastrointest Endosc 83: 92-100, 2016.

45. Ishimura N, Sumi $S$, Okada M, et al. Ankylosaurus back sign: novel endoscopic finding in esophageal eosinophilia patients indi- cating proton pump inhibitor response. Endosc Int Open 6: E165E172, 2018 Feb.

46. Nielsen JA, Lager DJ, Lewin M, Rendon G, Roberts CA. The optimal number of biopsy fragments to establish a morphologic diagnosis of eosinophilic esophagitis. Am J Gastroenterol 109: 515$520,2014$.

47. Hui CK, Hui NK. A Prospective Study on the Prevalence, Extent of Disease and Outcome of Eosinophilic Gastroenteritis in Patients Presenting with Lower Abdominal Symptoms. Gut Liver 12: 288296, 2018.

48. Pesek RD, Reed CC, Collins MH. Association Between Endoscopic and Histologic Findings in a Multicenter Retrospective Cohort of Patients with Non-esophageal Eosinophilic Gastrointestinal Disorders. Dig Dis Sci 65: 2024-2035, 2020.

49. Hurrell JM, Genta RM, Melton SD. Histopathologic diagnosis of eosinophilic conditions in the gastrointestinal tract. Adv Anat Pathol 18: 335-348, 2011.

50. Genevay M, Rubbia-Brandt L, Rougemont AL. Do eosinophil numbers differentiate eosinophilic esophagitis from gastroesophageal reflux disease? Arch Pathol Lab Med 134: 815-825, 2010.

51. Dellon ES. Eosinophilic esophagitis: diagnostic tests and criteria. Curr Opin Gastroenterol 28: 382-388, 2012.

52. Lee $S$, de Boer WB, Naran A, et al. More than just counting eosinophils: proximal oesophageal involvement and subepithelial sclerosis are major diagnostic criteria for eosinophilic oesophagitis. J Clin Pathol 63: 644-647, 2010.

53. Spechler SJ, Konda V, Souza R. Can Eosinophilic Esophagitis Cause Achalasia and Other Esophageal Motility Disorders? Am J Gastroenterol 113: 1594-1599, 2018.

54. Wen T, Stucke EM, Grotjan TM, et al. Molecular diagnosis of eosinophilic esophagitis by gene expression profiling. Gastroenterology 145: 1289-1299, 2013.

55. Dellon ES, Yellore V, Andreatta M, Stover J. A single biopsy is valid for genetic diagnosis of eosinophilic esophagitis regardless of tissue preservation or location in the esophagus. J Gastrointestin Liver Dis 24: 151-157, 2015.

56. Dellon ES, Veerappan R, Selitsky SR, et al. A Gene Expression Panel is Accurate for Diagnosis and Monitoring Treatment of Eosinophilic Esophagitis in Adults. Clin Transl Gastroenterol 8: e 74, 2017.

57. Matsushita $T$, Maruyama $M$, Ishikawa $N$, et al. The number and distribution of eosinophils in the adult human gastrointestinal tract: a study and comparison of racial and environmental factors. Am J Surg Pathol 39: 521-527, 2015.

58. DeBrosse CW, Case JW, Putnam PE, Collins MH, Rothenberg ME. Quantity and distribution of eosinophils in the gastrointestinal tract of children. Pediatr Dev Pathol 9: 210-218, 2006.

59. Laserna-Mendieta EJ, Casabona S, Guagnozzi D, et al. Efficacy of proton pump inhibitor therapy for eosinophilic oesophagitis in 630 patients: results from the EoE connect registry. Aliment Pharmacol Ther 52: 798-807, 2020.

60. Pineton de, Chambrun G, Gonzalez F, Canva JY, et al. Natural history of eosinophilic gastroenteritis. Clin Gastroenterol Hepatol 9 (11): 950-956.e1, 2011.

61. Dellon ES, Liacouras CA, Molina-Infante J, et al. Updated International Consensus Diagnostic Criteria for Eosinophilic Esophagitis: Proceedings of the AGREE Conference. Gastroenterology 155: 1022-1033.e10, 2018.

62. Hirano I, Chan ES, Rank MA, et al. AGA Institute and the Joint Task Force on Allergy-Immunology Practice Parameters Clinical Guidelines for the Management of Eosinophilic Esophagitis. Gastroenterology 158: 1776-1786, 2020.

63. Ishimura N, Ishihara $S$, Kinoshita Y. Sustained Acid Suppression by Potassium-Competitive Acid Blocker (P-CAB) May Be An Attractive Treatment Candidate for Patients with Eosinophilic Esoph- 
agitis. Am J Gastroenterol 111: 1203-1204, 2016.

64. Kuzumoto T, Tanaka F, Sawada A, et al. Vonoprazan shows efficacy similar to that of proton pump inhibitors with respect to symptomatic, endoscopic, and histological responses in patients with eosinophilic esophagitis. Esophagus 18: 372-379, 2021.

65. Shoda T, Matsuda A, Nomura I, et al. Eosinophilic esophagitis versus proton pump inhibitor-responsive esophageal eosinophilia: Transcriptome analysis. J Allergy Clin Immunol 139: 2010-2013.e 4, 2017.

66. van Rhijn BD, Weijenborg PW, Verheij J, et al. Proton pump inhibitors partially restore mucosal integrity in patients with proton pump inhibitor-responsive esophageal eosinophilia but not eosinophilic esophagitis. Clin Gastroenterol Hepatol 12: 1815-1823.e2, 2014.

67. Frazzoni M, Penagini R, Frazzoni L, et al. Role of Reflux in the Pathogenesis of Eosinophilic Esophagitis: Comprehensive Appraisal With Off- and On PPI Impedance-pH Monitoring. Am J Gastroenterol 114: 1606-1613, 2019.

68. Lucendo AJ, Miehlke S, Schlag C, et al. Efficacy of Budesonide Orodispersible Tablets as Induction Therapy for Eosinophilic Esophagitis in a Randomized Placebo-Controlled Trial. Gastroenterology 157: 74-86.e15, 2019.

69. Andreae DA, Hanna MG, Magid MS, et al. Swallowed Fluticasone Propionate Is an Effective Long-Term Maintenance Therapy for Children With Eosinophilic Esophagitis. Am J Gastroenterol 111: 1187-1189, 2016.

70. Straumann A, Conus S, Degen L, et al. Long-term budesonide maintenance treatment is partially effective for patients with eosinophilic esophagitis. Clin Gastroenterol Hepatol 9: 400-409.e1, 2011.

71. Dellon ES, Woosley JT, Arrington A, et al. Rapid Recurrence of Eosinophilic Esophagitis Activity After Successful Treatment in the Observation Phase of a Randomized, Double-Blind, DoubleDummy Trial. Clin Gastroenterol Hepatol 18: 1483-1492.e2, 2020.

72. Liacouras CA, Furuta GT, Hirano I, et al. Eosinophilic esophagitis: updated consensus recommendations for children and adults. J Allergy Clin Immuno 128: 3-20.e6, 2011.

73. Gonsalves N, Yang GY, Doerfler B, Ritz S, Ditto AM, Hirano I.
Elimination diet effectively treats eosinophilic esophagitis in adults; food reintroduction identifies causative factors. Gastroenterology 142: 1451-1459.e1, 2012.

74. Sunkara T, Rawla P, Yarlagadda KS, Gaduputi V. Eosinophilic gastroenteritis: diagnosis and clinical perspectives. Clin Exp Gastroenterol 12: 239-253, 2019.

75. Schwartz DA, Pardi DS, Murray JA. Use of montelukast as steroid-sparing agent for recurrent eosinophilic gastroenteritis. Dig Dis Sci 46: 1787-1790, 2001.

76. De Maeyer N, Kochuyt AM, Van Moerkercke W, Hiele M. Montelukast as a treatment modality for eosinophilic gastroenteritis. Acta Gastroenterol Belg 74: 570-575, 2011.

77. Greuter T, Hirano I, Dellon ES. Emerging therapies for eosinophilic esophagitis. J Allergy Clin Immunol 145: 38-45, 2020.

78. Grandinetti T, Biedermann L, Bussmann C, Alex Straumann A, Hruz P. Eosinophilic Gastroenteritis: Clinical Manifestation, Natural Course, and Evaluation of Treatment with Corticosteroids and Vedolizumab. Dig Dis Sci 64: 2231-2241, 2019.

79. Markowitz JE, Jobe L, Miller M, Frost C, Laney Z, Eke R. Safety and Efficacy of Reslizumab for Children and Adolescents With Eosinophilic Esophagitis Treated for 9 Years. J Pediatr Gastroenterol Nutr 66: 893-897, 2018.

80. Hirano I, Collins MH, Assouline-Dayan Y, et al. RPC4046, a Monoclonal Antibody Against IL13, Reduces Histologic and Endoscopic Activity in Patients With Eosinophilic Esophagitis. Gastroenterology 156: 592-603.e10, 2019.

81. Sastre J, Dávila I. Dupilumab: A New Paradigm for the Treatment of Allergic Diseases. J Investig Allergol Clin Immunol 28: 139150, 2018.

82. Dellon ES, Peterson KA, Murray JA, et al. Anti-Siglec-8 Antibody for Eosinophilic Gastritis and Duodenitis. N Engl J Med 383: 1624-1634, 2020.

The Internal Medicine is an Open Access journal distributed under the Creative Commons Attribution-NonCommercial-NoDerivatives 4.0 International License. To view the details of this license, please visit (https://creativecommons.org/licenses/ by-nc-nd/4.0/).

(C) The Japanese Society of Internal Medicine Intern Med Advance Publication 